\title{
Immunodeficiency and infantile bone and joint infection
}

\author{
KEN N. KUO, * G. C. LLOYD-ROBERTS, I. M. ORME, and J. F. SOOTHILL \\ From the Department of Orthopaedics, The Hospital for Sick Children, and the Department of Immunology, \\ Institute of Child Health, London
}

\begin{abstract}
Kuo, K. N., Lloyd-Roberts, G. C., Orme, I. M., and Soothill, J. F. (1975). Archives of Disease in Childhood, 50,51. Immunodeficiency and infantile bone and joint infection. Fifteen patients with infantile bone and joint infections were studied immunologically and clinically, 3 at the time of illness and 12 later. Abnormality of immunoglobulins, or complement, or phagocytes was found in 9 patients; 6 were within normal limits for the tests undertaken. Immunodeficiency is probably responsible for the subdued clinical signs of infection and for delayed diagnosis in some patients. It was also related to the extent of femoral head damage in infective arthritis of the hip and to the incidence of wound infection in late elective surgery.
\end{abstract}

A subdued clinical response to infection is common in immunodeficiency. Bone and joint infections during the first year are often characterized by such a reaction so that both the constitutional and regional signs fail to reflect the severity of the underlying cause. This may delay the diagnosis and the initiation of appropriate treatment, with the result that bone destruction is excessive and permanent disability follows (Eyre-Brooke, 1960; Lloyd-Roberts, 1960; Roberts, 1970).

The mechanisms responsible for the inflammatory effects of infection include antibody, complement, and phagocytes, which are also important for immunity to septicaemic illness. There is some evidence of functional immaturity of the latter two at birth, especially in the premature infant (Miller, 1969), and the antibody response is limited by lack of previous antigenic stimulus. But bone and joint infection occurs in patients with gross immunodeficiency, so it is possible that immunodeficiency, specific or nonspecific, permanent or transient, other than that of youth or prematurity may contribute to the subdued clinical response.

We report 3 infants with bone and joint infections studied at the time of their illness and a retrospective

Received 29 May 1974.

^Present address: Department of Orthopaedic Surgery, RushPresbyterian-St. Luke's Medical Center, 1753 W. Congress Parkway, Chicago, Illinois 60612 . investigation of patients previously treated in this hospital for this syndrome.

\section{Patients}

Three infants with bone or joint infections before the age of one year were studied at the time of the infection. All other patients seen for the late effects of purulent arthritis or bone infection in the first year of life were identified from the hospital registry. Those in whom tuberculosis was diagnosed, and those in whom a neurological lesion, such as meningomyelocele was likely to predispose to bone infection, were excluded, leaving 24. 3 who came from overseas were not contacted. Of the other 21, 12 attended for examination, 3 declined, and 6 did not reply to the request. There was no report of death in the retrospective study, though 2 of the prospective patients have died. All the retrospective patients, except Case 4, had been treated elsewhere and were referred here because of persistent disability. The site of infection, sex, and age of each patient are shown in the Table. An infection history of the patient and his family was taken. The patient was examined for gait, range of movement, and shortening, the affected joint was $x$-rayed, and venous blood was taken.

Immunoglobulins were measured by the radial diffusion method and the results, expressed in $\mathrm{IU} / \mathrm{ml}$, are compared with the values for healthy British children reported by Hobbs (1970). Isoagglutinins were titrated against $A$ and $B$ cells and where both were detected the higher value $\left(-\log _{2}\right.$ titre) is reported (there were no group AB patients). ASO and AST were titrated using Wellcome reagents and standards. C3 was measured by the radial diffusion method and values are expressed as 
Age, site, organism, and outcome of bone an

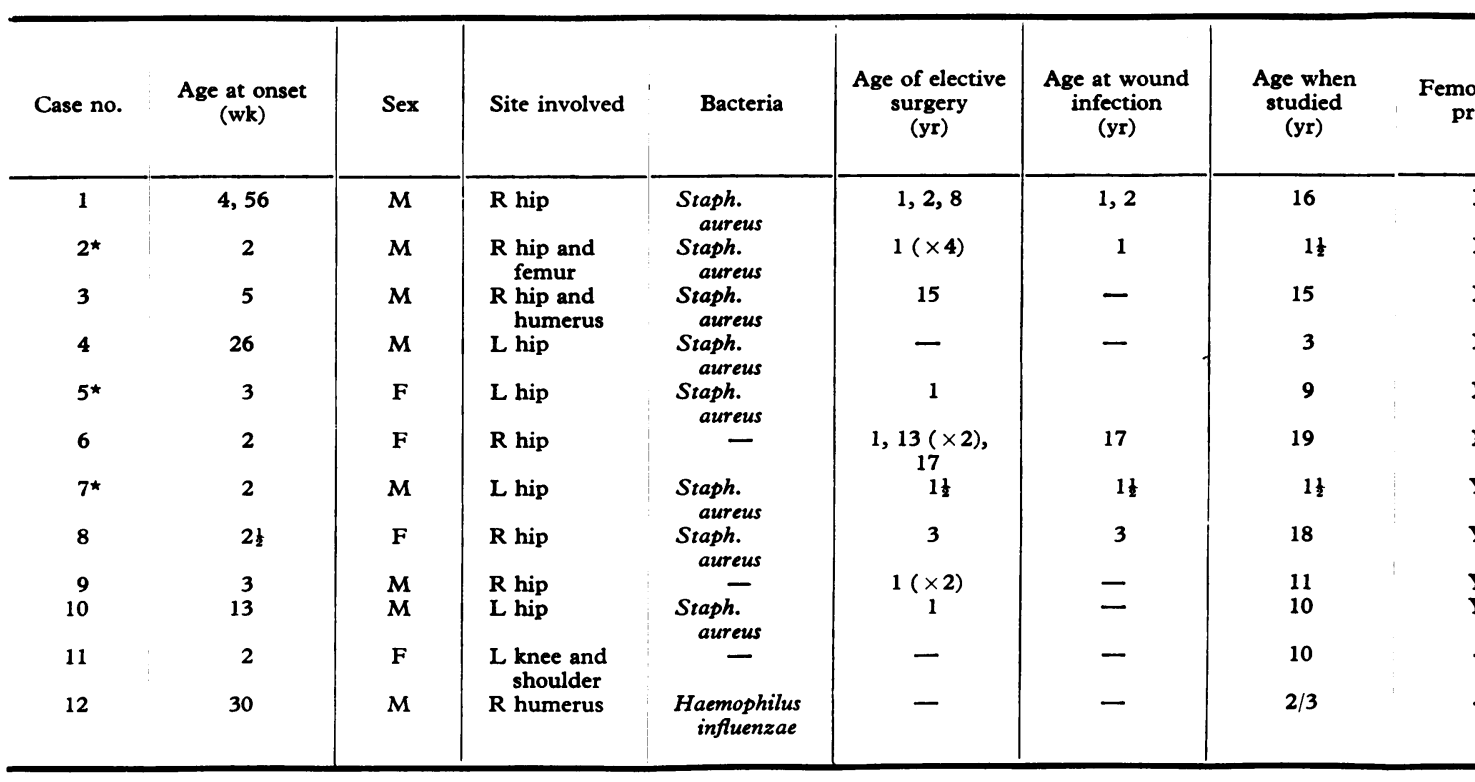

^Premature.

$t<$ mean -2 SD for age.

$\ddagger$ Low in normal range.

$\%$ of a serum standard; some control data are reported by Ngu and Soothill (1969). Opsonization by the patient's serum of yeast particles for phagocytosis by normal human polymorphs was measured by the method of Miller et al. (1968); values are expressed as \% of serum from healthy adults, measured in parallel. Bacterial (Oxford staphylococcus) phagocytosis and killing were studied by the plate count method of Quie et al. (1967); intracellular bacteria at $20 \mathrm{~min}$ (phagocytosis) and intracellular bacteria at 140 min divided by intracellular bacteria at $20 \mathrm{~min}$ (bacterial killing) are expressed as \% of values obtained with healthy adult's polymorphs run in parallel.

\section{Results}

Patients studied prospectively. Case 13 developed osteomyelitis of both femora, one tibia, and both humeri after severe gastroenteritis for which intravenous infusion was given at 5 weeks of age. Klebsiella was grown from blood culture and the left femoral lesion. The left hip was aspirated and gentamicin was given. The left hip was seen to be dislocated at 2 months (Fig. 1), but reduction was obtained. Residual flexion contracture of both hips occurred. Immunoglobulin estimation 8 days after the gastroenteritis began gave low values of $\operatorname{IgM}$ (10 and $11 \mathrm{IU} / \mathrm{ml}$-two samples studied), but normal
IgG (80 and $96 \mathrm{IU} / \mathrm{ml})$ and $\mathrm{IgA}(20$ and $19 \mathrm{IU} / \mathrm{ml})$. In the next 4 weeks IgG rose to $100 \mathrm{IU}$ and IgM to $182 \mathrm{IU}$, but then fell progressively; at 5 months, when he was well apart from residual hip disability, IgG was $52 \mathrm{IU}$, (low-normal value) and IgM $32 \mathrm{IU}$ (low value). IgA fell progressively during this time to the low value of $2 \cdot 5$ IU. He had a high neutrophil response, but otherwise his blood count was normal, as was lymphocyte PHA response and polymorph NBT test. This boy, therefore, had immunoglobulin deficiency of the common, varied, unclassified type (WHO). Unfortunately, he has failed to attend for follow-up since. The gastrointestinal infection and intravenous infusions provided a probable source of septicaemic infection.

Case 14 presented with exfoliative skin rash, diarrhoea, and insufficient weight gain. She required intravenous infusion. She developed a skin abscess and at 15 weeks septic arthritis of the hip and osteomyelitis of the humerus, all of which grew staphylococcus. Her serum and that of her mother, grandfather who also had osteomyelitis, and great-grandmother were defective at opsonization of yeast for phagocytosis (Miller et al., 1968). In spite of plasma infusions and antibiotics she died. Necropsy showed evidence suggestive of specific immunodeficiency. Studies of her and her family 
nfection in 12 infants, and results of immunological tests

\begin{tabular}{|c|c|c|c|c|c|c|c|c|c|}
\hline \multirow{2}{*}{\multicolumn{3}{|c|}{$\underset{(I U / m)}{\text { Immunoglobulin }}$}} & \multirow{3}{*}{$\underset{\left(-\log _{2} \text { titre }\right)}{\text { ASO }}$} & \multirow{3}{*}{$\begin{array}{c}\mathrm{AST} \\
\left(-\log _{2} \text { titre }\right)\end{array}$} & \multirow{3}{*}{$\begin{array}{c}\mathrm{C} 3 \\
\text { (\% standard) }\end{array}$} & \multirow{3}{*}{$\begin{array}{c}\text { Opsonization } \\
\text { patient/control } \\
(\%)\end{array}$} & \multirow{2}{*}{\multicolumn{2}{|c|}{$\frac{\text { Intracellular bacteria }}{\text { Patient/control ( } \%)}$}} & \multirow{3}{*}{$\begin{array}{c}\text { Anti-A or } \\
\text { anti-B } \\
\left(-\log _{2}\right)\end{array}$} \\
\hline & & & & & & & & & \\
\hline$I_{\mathbf{g G}}$ & IgA & $\operatorname{Ig} M$ & & & & & $20 \mathrm{~min}$ & $140 \mathrm{~min} / 20 \mathrm{~min}$ & \\
\hline 226 & +4 & 106 & 6 & 3 & 140 & 86 & 67 & 129 & 8 \\
\hline$\ddagger 70$ & $† 18$ & 138 & 5 & 4 & 116 & 105 & 97 & 145 & 3 \\
\hline$\ddagger 88$ & +25 & 166 & 7 & 5 & 108 & 114 & 92 & 82 & 7 \\
\hline+61 & 28 & $\dagger 37$ & 7 & 3 & 120 & 92 & 108 & 100 & 7 \\
\hline 97 & +31 & 75 & 8 & 4 & 84 & 99 & 109 & 120 & 9 \\
\hline 189 & 166 & 150 & 7 & 4 & 96 & 118 & 84 & 120 & 8 \\
\hline$\ddagger 67$ & +18 & 97 & 6 & 3 & 248 & 110 & 110 & 121 & 5 \\
\hline 150 & 101 & 277 & 6 & 3 & 240 & 111 & 141 & 75 & 9 \\
\hline$\ddagger 79$ & $¥ 57$ & 184 & 7 & 4 & 100 & 90 & 88 & 91 & 10 \\
\hline 85 & 69 & 75 & 7 & 5 & 120 & 83 & 85 & 117 & 11 \\
\hline 116 & 115 & 131 & 8 & 5 & 121 & 68 & 160 & 93 & 9 \\
\hline$\ddagger 42$ & 195 & 648 & 6 & 5 & 320 & 112 & 91 & 122 & 7 \\
\hline
\end{tabular}

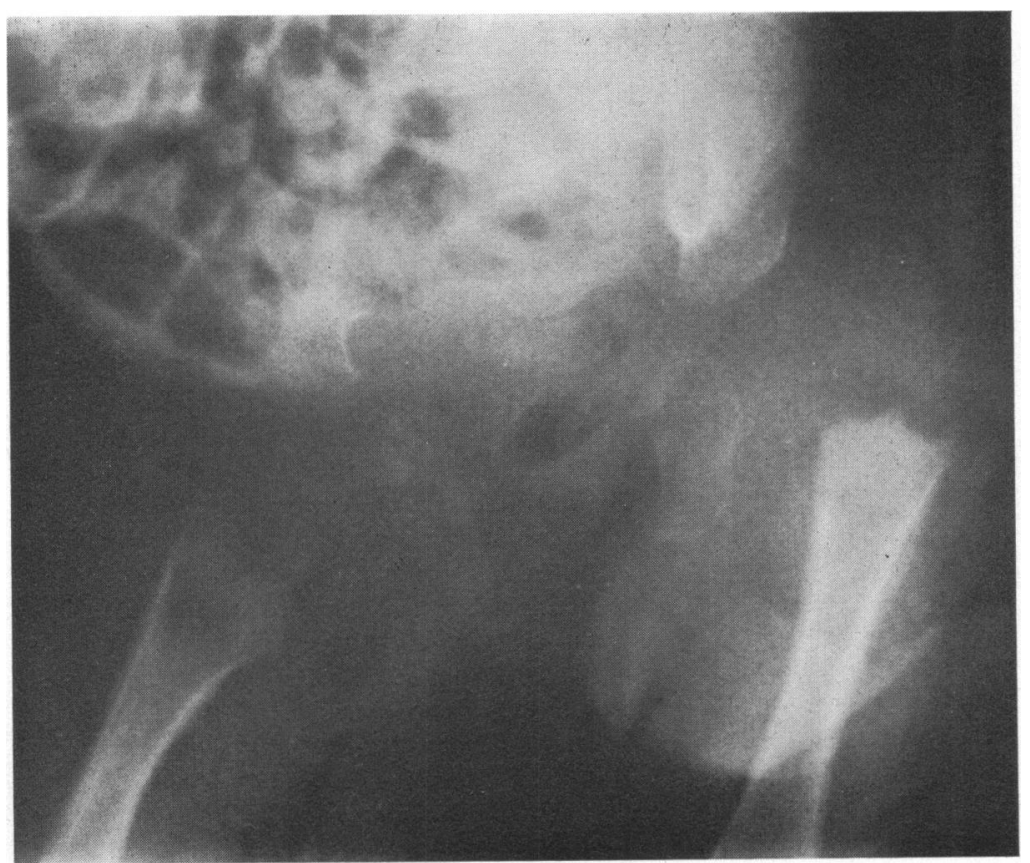

FIG. 1.-Case 13. Immunodeficiency, common varied-at age 2 months. X-ray showing both femora infected and left hip dislocated. 
will be reported in detail (Scott et al., 1975). Her skin was a likely site of entry of infection.

Case 15 is patient 1 of the series with chronic granulomatous disease reported by Thompson and Soothill (1970). He had many lymph node and other soft tissue infections, as well as staphylococcal osteomyelitis at 9 months. His syndrome is typical of this disease and the polymorph defect was shown by a qualitative NBT test in both him and his mother. Serum immunoglobulins were high, IgG $400 \mathrm{IU} / \mathrm{ml}$, IgA $360 \mathrm{IU} / \mathrm{ml}$, and IgM $248 \mathrm{IU} / \mathrm{ml}$. Isoagglutinin was detected at only a $1 / 1$ dilution. $\mathrm{He}$ died at one year of age.

Our prospective studies provided examples of defects of all three links in the antibody, complement, phagocyte chain associated with osteomyelitis of infancy, but all had severe general illness. We therefore undertook the retrospeciive studies of other infants with destructive bone and joint infection who had not been so generally or severely ill to see whether less severe immunodeficiency occurred there too.

Retrospective study. Of the 12 patients studied (see Tdble), 8 were male; 3 were premature, one of whom (Case 7) had had umbilical catheterization which was thought to be the source of infection. Case 4 had $\beta$-methylcrotonylglycinuria and had received many intravenous infusions, one of which had been associated with local infection and staphylococcal septicaemia, 3 months before the hip infection was diagnosed. Case 10 had received methylene blue intravenously for methylhaemoglobinaemia.

All but Cases 11 and 12 had hip infections (Case 3 had osteomyelitis of the humerus and Case 2 of the femur, in addition). In 3 there is no record of the infecting organism but Staphylococcus aureus was grown from all others except Case 12, who had Haemophilus influenzae. All 10 with hip disease had residual limp and leg shortening; the head of the femur was identifiable on $x$-ray in 4 . In 2 of those in whom it was destroyed (Cases 1 and 6) the hip joint had fused spontaneously, and progressive shortening and pain is now regarded as indicating arthrodesis of the hip in Case 3. Case 1 had two episodes of staphylococcal arthritis of the hip one year apart; the head of the femur was detectable

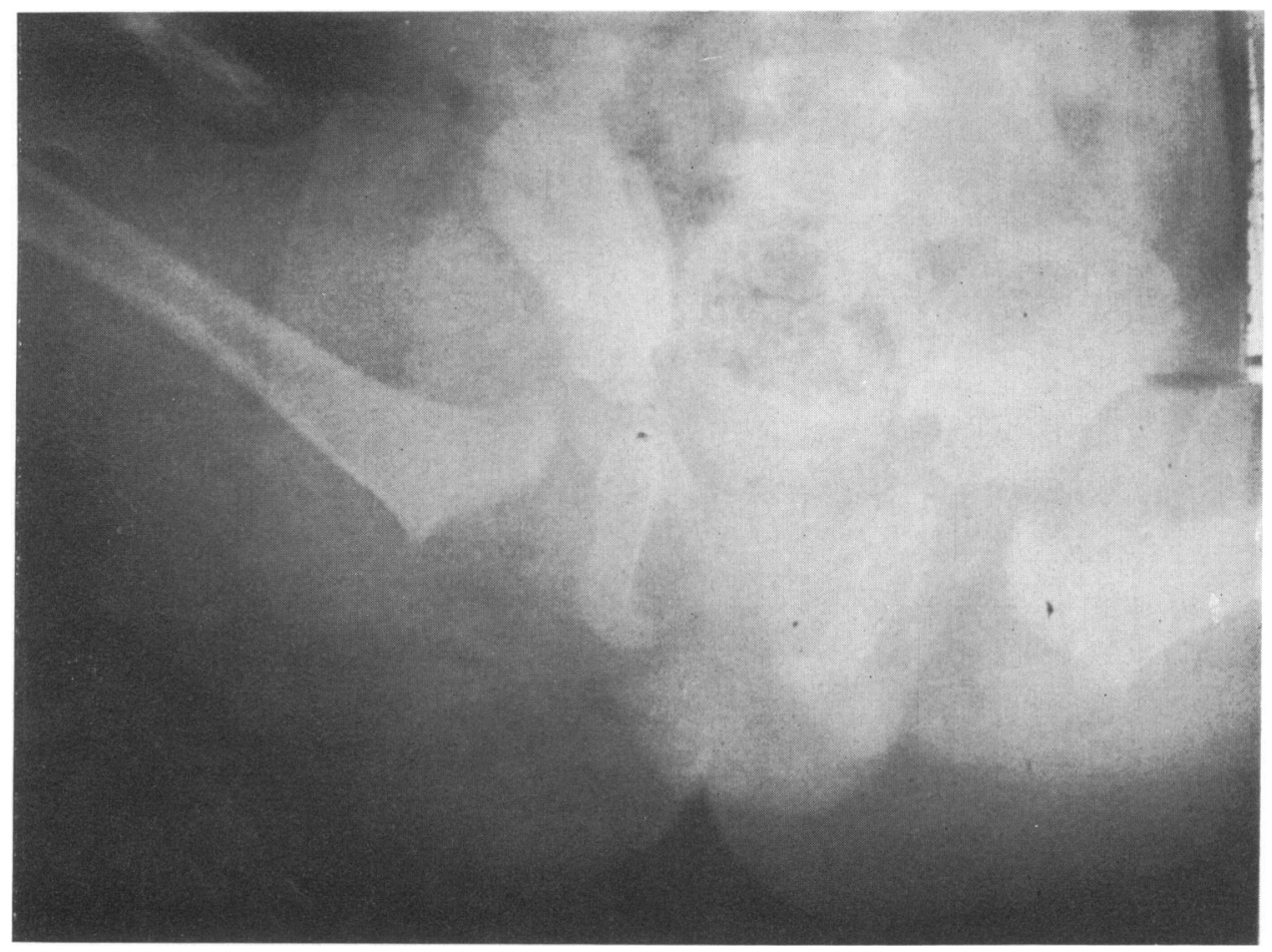

FIG. 2.-Case 1. X-ray of right hip after first septic arthritis at 4 weeks showing ossified femoral head and hip joint reduced. 
after the first attack (Fig. 2) but it was no longer detectable after the second attack (Fig. 3).

The number of elective reconstructive operations, the age at which they were done, and the occurrence of wound infection are shown in the Table. 18 operations were done on 9 patients and 6 wound infections occurred in 5 patients, an incidence far higher than our usual experience of less than $1 \%$. Of the 9 patients followed up to 3 years or more, 3 have subsequently had tonsillectomy for frequent

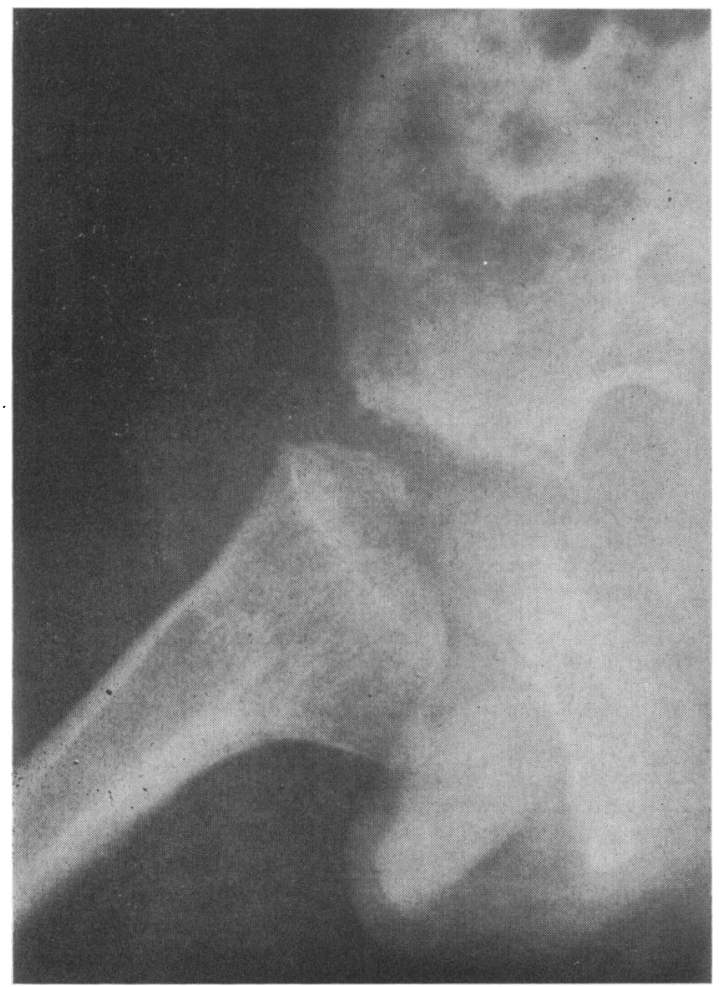

FIG. 3.-Case 1. X-ray at 1 year after second infection. Right femoral head no longer present.

sore throats and a fourth had the conventional indications with repeated lymphadenitis, one of which was biopsied.

The patients's bacterial phagocytosis and killing and yeast opsonization were all comparable with the parallel control values and fell within mean $\pm 2 S D$ for a larger series of healthy adults. Three C3 values were higher than the range of values observed by Ngu and Soothill (1969), but none were low. We therefore found no evidence for phagocytosis and complement abnormalities by these limited tests. A number of patients showed evidence of abnormality of immunoglobulin concentration as compared with the study of healthy British children reported by Hobbs (1970). Only Case 12 showed a high value, but 5 had low IgA concentrations; Case 9 was just above mean -2 SD for IgG and IgA, and Case 4 with $\beta$-methylcrotonylaciduria had IgG, $\operatorname{IgM}$, and IgA at the lower limits of normal. 3 of the patients with low IgA had been premature, but it is unlikely that this can be related to a $\operatorname{low} \operatorname{IgA}$ concentration at 9 years (Case 5). Case 1 (the lowest) and Case 3 still had IgA deficiency at 16 and 15 years, and were not premature.

The presence or absence of femoral head on $x$-ray provides an objective indication of severity of damage, and it appears to be related to immunoglobulin concentration - of the 10 patients who had hip disease, 5 of the 6 patients with low levels have lost their femoral heads but 3 of the 4 with normal levels have not. Even with these small numbers this relation approaches significance at the $5 \%$ level on Fisher's exact test. Isoagglutinin, ASO, and AST values were probably normal and were not obviously related to other findings.

\section{Discussion}

The 3 prospective patients confirm our expectations that defects of any stage of the antibody, complement, phagocyte system may be associated with osteomyelitis. The usual route of bone infection is by the blood stream, and $\operatorname{IgM}$ is thought to be of special relevance in controlling septicaemic illness (Hobbs, Milner, and Watt, 1967), so it is likely that this is the relevant defect in Case 13. It is interesting that recovery was associated with a rise of IgM, but this and IgA fell afterwards.

Opsonization of yeasts by serum of Case 14 and of her mother for phagocytes by normal polymorphs was defective. This defect, associated with dermatitis and infections, has been ascribed to functional abnormality of the fifth component of complement (Miller and Nilsson, 1970). Case 14 probably had other defects as well. The polymorph defect of bacterial killing in chronic granulomatous disease, which Case 12 suffered, is well known to lead to osteomyelitis.

In spite of this confirmation that a defect anywhere in the chain can lead to bone infection in infancy, in our retrospective study we found evidence only of immunoglobulin deficiency and in all but one patient that was of $\operatorname{IgA}$. $\operatorname{IgA}$ is unlikely to be responsible itself for the protection against bone infection, but it is the slowest immunoglobulin to reach adult levels, so it is a good case finder for mild degrees of more generalized and transient immunodeficiency. A failure to make IgM anti- 
body is one possibly related defect which could have been responsible, but all patients made isoagglutinins, which are IgM. Since some immunodeficiency is undoubtedly transient, it is likely that some of the other patients also had had immunodeficiency no longer detectable at the time of follow-up, but the normal relative hypofunction of the immunity mechanisms of the neonate, which is worse in prematures, would also be expected to contribute to susceptibility to infection and to the subdued clinical response in early life. 3 were premature but we find it difficult to relate IgA deficiency at 9 years entirely to this. The child with IgG and IgM deficiency had $\beta$-methylcrotonylglycinuria: immunoglobulin deficiency has been described in the similar ketotic hyperglycinaemia (Childs et al., 1961), so this could be the cause here. For the rest, differences due to multifactorial inheritance must be assumed to operate. Further evidence for a mild degree of immunodeficiency is provided by the high incidence of tonsillectomy (or cervical lymph node biopsy) which is also associated with low levels of IgA (Donovan and Soothill, 1973). The remarkably high incidence of wound infections in reconstructive operations could also be an effect of the immunodeficiency, or of chronic carriage of pathogens, or both.

The patient with the lowest IgA (Case 1) had two separate episodes of hip infection and two separate wound infections, which supports the possibility of a relation. This relation between immunodeficiency and septic arthritis should not be confused with the relation between panhypo- $\gamma$-globulinaemia (Lawrence, 1971) or IgA deficiency (Cassidy and Burt, 1967) and arthritis of a presumed allergic kind.

The trend for greater hip damage with loss of head of femur, in the more immunodeficient patients, is open to two interpretations. Perhaps the immunodeficiency led to a more destructive form of local infection (though the reverse is also possible) or perhaps the infection was particularly subdued in these patients so that it was longer before a diagnosis was made and greater damage occurred because of the delay of treatment. We did not observe the severity of the response to the primary infection of this retrospective group because 11 of the 12 had their initial treatment elsewhere.

This study confirms the view that the subdued clinical evidence of bone and joint infection is related to hypofunction of the antibody, comple- ment, phagocyte pathway, and suggests that immunodeficiency beyond that of the normal neonate may often contribute. Since such immunodeficiency is compatible with a full life, apart from the effects of the damaged hip, alertness of family doctors, paediatricians, and orthopaedic surgeons to this possibility is important to minimize hip damage and permanent disability.

We are grateful to Mrs. B. A. M. Harvey for the bacterial killing and opsonization values.

\section{REFERENCES}

Cassidy, J. T., and Burt, A. (1967). Isolated IgA deficiency in juvenile rheumatoid arthritis. Arthritis and Rheumatism, 10, 272 .

Childs, B., Nyhan, W. L., Borden, M., Bard, L., and Cooke, R. E. (1961). Idiopathic hyperglycinemia and hyperglycinuria: a new disorder of amino acid metabolism, I. Pediatrics, 27, 522.

Donovan, R., and Soothill, J. F. (1973). Immunological studies in children undergoing tonsillectomy. Clinical and Experimental Immunology, 14, 347.

Eyre-Brook, A. L. (1960). Septic arthritis of the hip and osteomyelitis of the upper end of the femur in infants. Fournal of Bone and foint Surgery, 42B, 11.

Hobbs, J. R. (1970). Simplified radial immunodiffusion. Association of Clinical Pathologists, Broadsheet, No. 68.

Hobbs, J. R., Milner, R. D. G., and Watt, P. J. (1967). Gamma-M deficiency predisposing to meningococcal septicaemia. British Medical fournal, 4, 583.

Lawrence, J. S. (1971). Rheumatic disease in hypogammaglobulinaemia. In Hypogammaglobulinaemia in the United Kingdom, p. 35. H.M.S.O., London.

Lloyd-Roberts, G. C. (1960). Suppurative arthritis of infancy: some observation upon prognosis and management. fournal of Bone and foint Surgery, 42B, 706.

Miller, M. E. (1969). Phagocytosis in the newborn infant; humoral and cellular factors. Fournal of Pediatrics, 74, 255.

Miller, M. E., and Nilsson, U. R. (1970). A familial deficiency of the phagocytosis-enhancing activity of serum related to a dysfunction of the fifth component of complement (C5). New England fournal of Medicine, 282, 354.

Miller, M. E., Seals, J., Kaye, R., and Levitsky, L. C. (1968). A familial, plasma-associated defect of phagocytosis : a new cause of recurrent bacterial infections. Lancet, 2, 60 .

Ngu, J. L., and Soothill, J. F. (1969). Immunoconglutinin and complement changes in children with acute nephritis. Clinical and Experimental Immunology, 5, 557.

Quie, P. G., White, J. G., Holmes, B., and Good, R. A. (1967). In vitro bacteriocidal capacity of human polymorphonuclear leukocytes; diminished activity in chronis granulomatous disease of childhood. Fournal of Clinical Investigation, 46, 668.

Roberts, P. H. (1970). Disturbed epiohyseal growth at the knee after ostcomyelitis in infancy. Fournal of Bone and foint Surgery, 52B, 692.

Scott, H., Moynahan, E. J., Risdon, R. A., Harvey, B. A. M., and Soothill, J. F. (1975). Familial opsonization defect associated with fatal infantile dermatitis, infections, and histiocytosis. Archives of Disease in Childhood. (In the press.)

Thompson, E. N., and Soothill, J. F. (1970). Chronic granulomatous disease: quantitative clinicopathological relationships. Archives of Disease in Childhood, 45, 24.

Correspondence to Professor J. F. Soothill, Department of Immunology, Institute of Child Health, 30 Guilford Street, London WC1N 1EH. 